\title{
Improving Power Flow Capacity of Transmission Lines Using DPFC with a PEM Fuel Cell
}

\author{
Jaydeep Chakravorty \\ Electrical Engineering Department \\ Indus University \\ Ahmedabad, India
}

\author{
Jyoti Saraswat \\ ALPLA India, Pvt. Ltd. \\ Dadra \& Nagar Havali \\ Gujarat, India
}

\begin{abstract}
The electrical power system is one complex architecture integrating generation, transmission, distribution, and utilization sections. The exponential increase in power requirements made this system more complex and dynamic. Providing good quality and uninterrupted power has become a challenge. In this respect, FACTS devices are playing a vital role in improving power quality and also in increasing the transmission capacity of lines. In this paper. Distributed Power Flow Controller (DPFC), with a PEM fuel cell, has been used in an IEEE-14 bus system to improve system power flow capacity. The proposed IEEE-14 bus with DPFC has been simulated in MATLAB/SIMULINK. The effects are exhibited and analyzed.
\end{abstract}

\section{Keywords-DPFC; PEM; power quality}

\section{INTRODUCTION}

Uninterrupted electrical power supply is a major requirement for the development of a country. To meet the increasing need of uninterrupted good quality power is a big challenge. Due to the increasing demand of power, power system networks are becoming very complex. With very fast increase in non-linear loads in the power system, the supply of good quality power has become a major problem. To cater these needs, FACTS devices are playing a very vital role in increasing the efficiency of the transmission system [1-2]. Studies conducted in improving power quality by incorporating FACTS devices can be seen in [3-11]. Various algorithms have also been developed with the help of which it is feasible now to efficiently place FACTS devices in the power system, something that has drastically reduced the cost of operation and also has improved the quality of power transfer [12-13]. This paper proposes a method to improve power transfer capability of the system with the proposed DPFC with a PEM fuel cell [14]. The optimal location of the proposed DPFC has been decided with the help of Artificial Algae Algorithm [15]. The complete proposed system has been simulated in MATLAB/SIMULINK and the result has been compared with the system without DPFC in it.

\section{TRANSMISSION LINE REPRESENTATION}

A simple representation of transmission line is show in Figure. 1 Between bus- $i$ and bus- $j$, the line admittance is $g_{i j}+j b_{i j}=\frac{1}{r_{i j}+j x_{i j}}$, and the bus voltages are $V_{i} \angle \delta_{i}$ and $V_{j} \angle \delta_{j}$ respectively. The real $\left(P_{i j}\right)$ and reactive $\left(Q_{i j}\right)$ power flowing from bus- $i$ to bus- $j$ can be written as:

$$
\begin{gathered}
P_{i j}=V_{i}^{2} g_{i j}-V_{i} V_{j}\left[g_{i j} \cos \delta_{i j}+b_{i j} \sin \delta_{i j}\right] \\
Q_{i j}=-V_{i}^{2}\left[b_{i j}+\frac{B_{s h}}{2}\right]-V_{i} V_{j}\left[g_{i j} \sin \delta_{i j}-b_{i j} \cos \delta_{i j}\right]
\end{gathered}
$$

where, $\delta_{i j}=\delta_{i}-\delta_{j}$.

Real power $P_{j i}$ and reactive power $Q_{j i}$ flowing from bus $j$ to bus $i$ are given by:

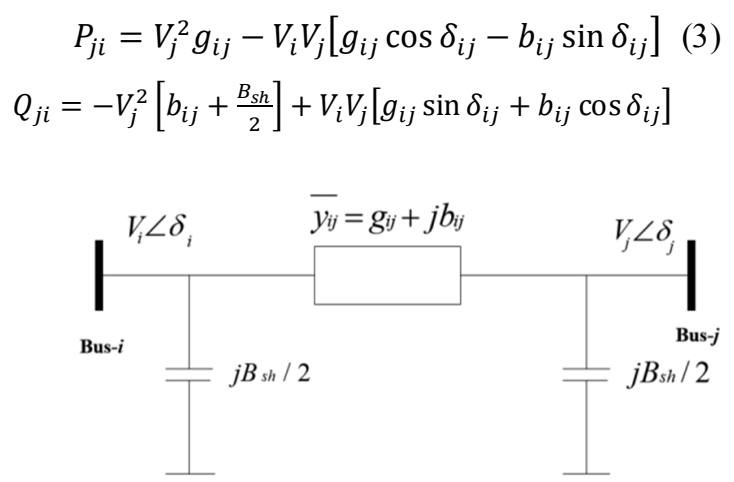

Fig. 1. Transmission line representation

\section{DPFC MODEL}

In this model, DPFC with a PEM fuel cell has been used. The complete representation DPFC with a PEM fuel cell has been discussed in [14]. The complete MATLAB model of is shown in Figure 2.

\section{IEEE-14 BUS SYSTEM}

The IEEE-14 bus system SIMULINK model is shown in Figure 3. The location of DPFC has been decided by the application of Artificial Algae Algorithm [15]. The numerical data and the parameters are taken from [16]. The proposed IEEE-14 bus system has 19 lines, 11 load buses, 1 slack bus and 2 generator buses.

\section{ARTIFICIAL ALGAE ALGORITHM}

The optimal location of DPFC has been has been determined by the application of artificial algae algorithm [15], which gives very good results for nonlinear optimization [17]. 
In this algorithm an artificial algae colony represents each individual. The process of this technique has three steps, Helical Movementt, Reproduction and Adaptation. After each cycle of operation, the population in the colonies is modified in the helical movement phase. It is assumed that the colony swims in all three dimensions in order to reach the light. Colony's energy will increase and its movement will slow down as it reaches the light. To increase the local search ability of the algorithm as the colonies approach the light, the algorithm starts searching the space with smaller and smaller steps. On the other hand, the colonies which are far away from the light will search the space with bigger steps, which in turn increases global search ability. Artificial algae algorithm has a strong balance between exploration and exploitation. The pseudo code is given in Figure 4.

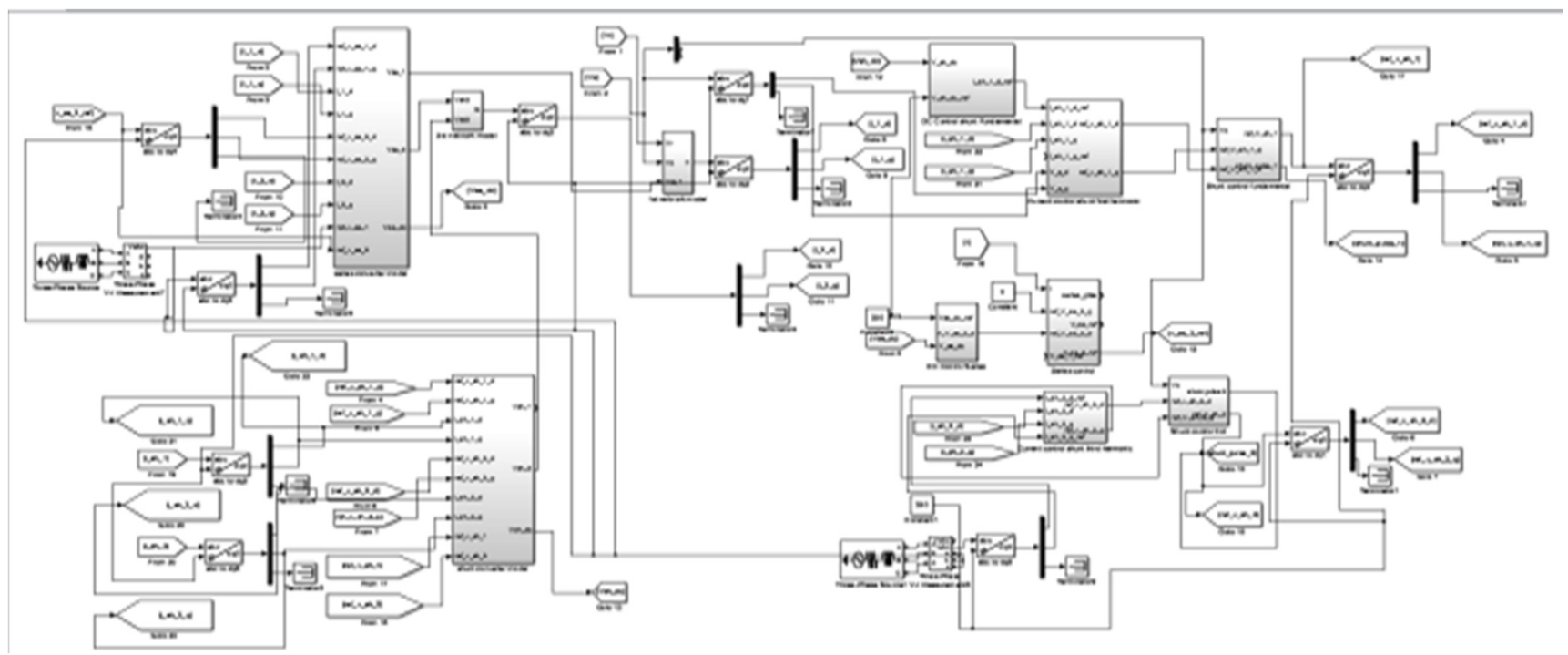

Fig. 2. DPFC with a PEM fuel cell [14]

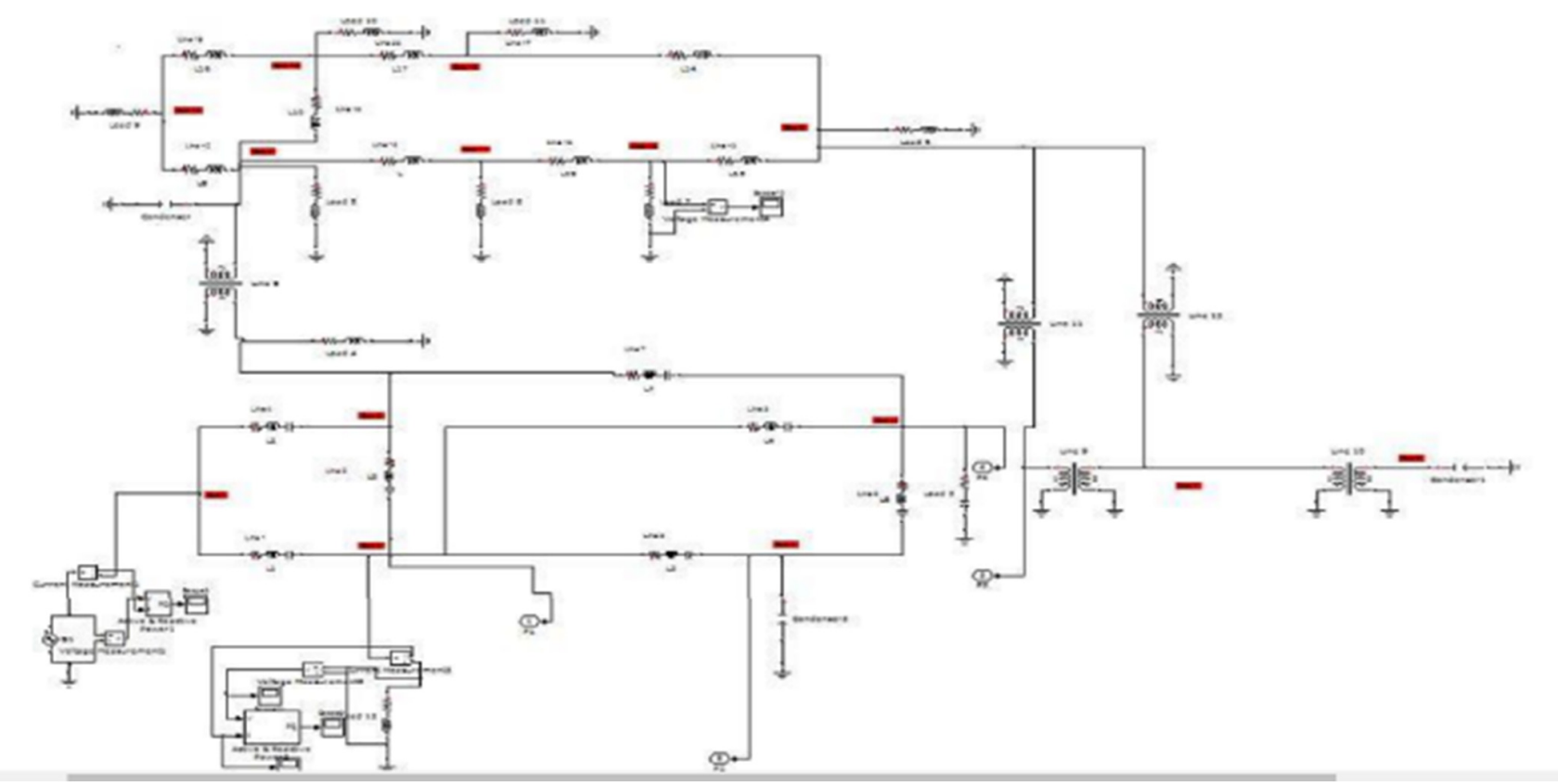

Fig. 3. IEEE-14 bus system

VI. RESULTS AND DISCUSSION

The voltage profile of the system with and without the application of DPFC when applied to the IEEE 14 bus system is shown in Figure 5. The optimal location of DPFC was obtained by the application of artificial algae algorithm. The IEEE 14 bus system was tested first without the DPFC in the system and then with the DPFC embedded in the system. 
1. To generate initial population with random solution of $n$ algal colonies.

2. Evaluate $f\left(x_{i}\right)$ for $i=1,2,3, \ldots \ldots, \mathrm{D}$

3. While the stopping condition is not reached

4. For $i=1$ to $n$

5 . While the energy of the $i$-th colony is not finished

6. Modify the colony

7. End while

8. End for

9. Apply Evolution strategy

10. Apply Adaptation strategy

11. End of while

Fig. 4. Artificial algae algorithm pseudo code

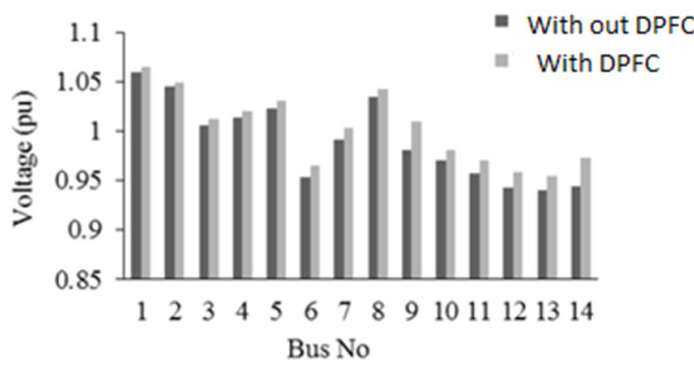

Fig. 5. Voltage profile

The real and reactive power loss values for normal load condition, $125 \%$ load and $150 \%$ load are shown in Table I and II respectively.

TABLE I. REAL POWER LOSS

\begin{tabular}{|l|c|c|c|c|c|c|} 
& \multicolumn{2}{|c|}{ Normal load } & \multicolumn{2}{c|}{$\mathbf{1 2 5 \%}$ load } & \multicolumn{2}{c|}{$\mathbf{1 5 0 \%}$ load } \\
\hline & $\begin{array}{c}\text { Without } \\
\text { DPFC }\end{array}$ & $\begin{array}{c}\text { With } \\
\text { DPFC }\end{array}$ & $\begin{array}{c}\text { Without } \\
\text { DPFC }\end{array}$ & $\begin{array}{c}\text { With } \\
\text { DPFC }\end{array}$ & $\begin{array}{c}\text { Without } \\
\text { DPFC }\end{array}$ & $\begin{array}{c}\text { With } \\
\text { DPFC }\end{array}$ \\
\hline $\begin{array}{c}\text { Real Power } \\
\text { Loss (MW) }\end{array}$ & 14.5 & 13.2 & 26.01 & 24.99 & 38.32 & 35.57
\end{tabular}

TABLE II. REACTIVE POWER LOSS

\begin{tabular}{|c|c|c|c|c|c|c|}
\hline & \multicolumn{2}{|c|}{ Normal load } & \multicolumn{2}{c|}{$\mathbf{1 2 5 \%}$ load } & \multicolumn{2}{c|}{$\mathbf{1 5 0 \%}$ load } \\
\hline & $\begin{array}{c}\text { Without } \\
\text { DPFC }\end{array}$ & $\begin{array}{c}\text { With } \\
\text { DPFC }\end{array}$ & $\begin{array}{c}\text { Without } \\
\text { DPFC }\end{array}$ & $\begin{array}{c}\text { With } \\
\text { DPFC }\end{array}$ & $\begin{array}{c}\text { Without } \\
\text { DPFC }\end{array}$ & $\begin{array}{c}\text { With } \\
\text { DPFC }\end{array}$ \\
\hline $\begin{array}{c}\text { Reactive Power } \\
\text { Loss (MW) }\end{array}$ & 29.3 & 28.5 & 69.45 & 67.3 & 98.23 & 96.6 \\
\hline
\end{tabular}

From the above results it can be concluded that by the proper application of DPFC in the system, its voltage profile can be improved. The application of the proposed DPFC with a PEM fuel cell has reduced the real and reactive power loss in the system at different load conditions.

\section{CONCLUSION}

In this paper, a 14 bus IEEE system with DPFC has been simulated in MATLAB/SIMULINK. It was observed that the power flow capacity of the system with DPFC is more than the one of the same system without DPFC. The simulation of the proposed system took a very long time to give the output. In the future, some modifications in the design of the system may be applied in order to reduce simulation time.

\section{REFERENCES}

[1] N. G. Hingorani, L. Gyugyi, Understanding FACTS: Concepts and technology of flexible AC transmission systems, IEEE Press, 2000

[2] ABB, Technologies that changed the world: FACTS, available at: https://new.abb.com/facts/about-facts/technologies-that-changed-theworld-facts

[3] L. Gyugyi, C. D. Schauder, S. L. Williams, T. R. Rietman, D. R. Torgerson, A. Edris, "The unified power flow controller: a new approach to power transmission control", IEEE Transactions on Power Delivery, Vol. 10, No. 2, pp. 1085-1092, 1995

[4] C. Chengaiah, R. V. S. Satyanarayana, "Power flow assesment in transmission lines using Simulink model with UPFC", International Conference on Computing, Electronics and Electrical Technologies, Kumaracoil, India, March 21-22, 2012

[5] Z. Huang, Y. Ni, C. M. Shen, F. F. Wu, S. Chen, B. Zhang, "Application of unified power flow controller in interconnected power systems: modeling, interface, control strategy, and case study", IEEE Transactions On Power Systems, Vol. 15, No. 2, pp. 817-823, 2000

[6] C. Chengaiah, R. V. S. Satyanarayana, G. V. Marutheswar, "Study on effect of UPFC device in electrical transmission system: power flow assessment", International Journal of Electrical and Electronics Engineering, Vol. 1, No. 4, pp. 66-70, 2012

[7] P. Kannan, S. Chenthur Pandian, "Case study on power quality improvement of thirty bus system with UPFC", International Journal of Computer and Electrical Engineering, Vol. 3, No. 3, pp. 417-420, 2011

[8] A. R. Bhowmik, C. Nandi, "Implementation of Unified Power Flow Controller (UPFC) for power quality improvement in IEEE 14-Bus System", International Journal of Circuit Theory and Applications, Vol. 2, No. 6, pp. 1889-1896, 2011

[9] E. Gholipour, S. Saadate, "Improving of transient stability of power systems using UPFC", IEEE Transactions on Power Delivery, Vol. 20, No. 2, pp. 1677-1682, 2005

[10] A. K. Sahoo, S. S. Dash, T. Thyagarajan, "An improved UPFC control to enhance power system stability", Modern Applied Science, Vol. 4, No. 6, pp. 37-48, 2010

[11] A. J. F. Keri, A. S. Mehraban, X. Lombard, A. Eiriachy, A. A. Edris, "Unified power flow controller (UPFC): modeling and analysis", IEEE Transactions on Power Delivery, Vol. 14, No. 2, pp. 648-654, 1999

[12] A. M. Vural, M. Tumay, "Steady State Analysis of Unified Power Flow Controller; Mathematical Modelling and Simulation Studies", IEEE Bologna Power Tech Conference, Bologna, Italy, June 23-26, 2003

[13] S. N. Singh, I. Erlich, "Locating unified power flow controller for enhancing power system loadability", International Conference on Future Power Systems, Amsterdam, Netherlands, November 18, 2005

[14] J. Chakravorty, J. Saraswat, V. Bhatia, "Modeling a distributed power flow controller with a PEM fuel cell for power quality improvement", Engineering, Technology \& Applied Science Research, Vol. 8, No. 1, pp. $2585-2589,2018$

[15] J. Charavorty, J. Saraswat, "Deciding optimal location of DPFC in transmission line using Artificial Algae Algorithm", Engineering, Technology \& Applied Science Research, Vol. 9, No. 2, pp. 39783980, 2019

[16] M. P. Aghababa, M. E. Akbari, A. M. Shotorbani, "An Efficient Modified Shuffled Frog Leaping Optimization Algorithm", International Journal of Computer Applications, Vol. 32, No. 1, pp. 26-30, 2011

[17] S. A. Uymaz, G. Tezel, E. Yel, "Artificial algae algorithm (AAA) for nonlinear global optimization”, Applied Soft Computing, Vol. 31, pp. 153-171, 2015 